\title{
Mineração
}

\section{Seleção de solos para a imobilização de arsênio}

\author{
Ana Cláudia Q. Ladeira \\ Dr., Pesquisadora, Depart. de Eng. Metalúrgica e de Materiais, UFMG \\ E-mail:aladeira@demet.ufmg.br
}

Virgínia Sampaio T. Ciminelli

Ph.D., Professora Titular, Depart. de Eng. Metalúrgica e de Materiais, UFMG

E-mail: ciminelli@demet.ufmg.br

Alessandro L. Nepomuceno

M.Sc., Engenheiro de Minas, Rio Tinto do Brasil Ltda

E-mail: alessandro.nepomuceno@rtb.riotinto.com.br

\section{Resumo}

Esse trabalho consistiu da realização de estudos comparativos da capacidade de retenção de arsênio de 3 amostras de solos do Estado de Minas Gerais e de 1 amostra de rejeito de minério aurífero oriundo da mina do Morro do Ouro, da Rio Paracatu Mineração S.A. A capacidade de retenção foi avaliada com base no levantamento de isotermas, através das quais foi calculado o carregamento máximo de arsênio em cada material. Foi realizada, também, a caracterização química e mineralógica desses sólidos de forma a determinar os minerais constituintes das amostras e, conseqüientemente, os principais adsorventes de arsênio. Finalmente, correlacionando a capacidade adsortiva de cada solo com seus constituintes mineralógicos, foi possível fazer a seleção dos solos mais adequados para a imobilização do arsênio.

Palavras-chave: arsênio, adsorção, solos, meio ambiente.

\begin{abstract}
This work aimed at investigating arsenic adsorption capacity of three soil samples from Minas Gerais region and one tailing sample from Morro do Ouro, a gold mine owned by Rio Paracatu Mineração S.A. Maximum adsorption capacities of the samples were determined by a Langmuir type equation. Chemical and mineralogical characterization were carried out in order to determine the main minerals responsible for the adsorption process. The arsenic adsorption capacities were then correlated with the samples constituents. Based on the adsorption data and on the samples constituents, it was possible to select an appropriated soil for arsenic immobilization.
\end{abstract}

Keywords: arsenic,adsorption, soils, environment.

Artigo recebido em 23/05/2002 e aprovado em 09/08/2002. 


\section{Introdução}

Elevadas concentrações de poluentes nos solos das regiões urbanas podem trazer sérios impactos ao meio ambiente, principalmente se alguns desses poluentes forem lixiviados atingindo aqüíferos superficiais ou subterrâneos. O processo de sorção de alguns poluentes nos solos ocorre na natureza de forma sistemática e, em geral, lentamente. Inicialmente os poluentes são adsorvidos nos solos através de troca iônica, interações eletrostáticas, forças de van der Waals ou ligações químicas estáveis e, através do envelhecimento do solo, podem vir a fazer parte da estrutura de alguns minerais. Quando não ocorre uma interação estável do poluente com o solo, pode, então, haver a migração do poluente, culminando com a contaminação da água de lençóis ou da superfície.

Os impactos negativos causados pelo arsênio aos solos e águas têm despertado grande interesse do público devido principalmente à contaminação de uma parcela significativa de populações vizinhas às fontes geradoras desse elemento (Rawlins et al., 1997). Uma das principais fontes de contaminação são as atividades de explotação de minérios sulfetados, que produzem resíduos sólidos ricos em arsênio. Esses resíduos são depositados na forma de pilhas de rejeito, pilhas de estéril e pilhas extintas de lixiviação. A dissolução de minerais de arsênio, como a arsenopirita, dispostos nessas pilhas, é uma fonte permanente de contaminação. Outra fonte provável de contaminação está relacionada aos precipitados de arsenatos metálicos utilizados como forma de disposição do arsênio solubilizado em processos hidrometalúrgicos. Também a lixiviação natural de solos típicos de regiões da Índia, Bangladesh e Mongólia, entre outros países, com background elevado em As, tem acarretado a contaminação de grandes volumes de água subterrânea, levando à contaminação de milhões de pessoas.

Em se tratando da solubilização de arsênio presente em rejeitos sólidos, a utilização de substratos inorgânicos que apresentam elevada capacidade de sorção tem sido estudada como uma opção para remoção e imobilização desse ele- mento. O uso de adsorventes inorgânicos é uma tentativa de se empregarem tecnologias mais eficazes e mais acessíveis economicamente às indústrias de extração mineral. Entre os minerais que apresentam propriedades adsorventes de arsênio encontram-se alguns argilominerais (Griffin et al., 1977, Lo et al., 1997), a alumina (Ghosh \& Yuan, 1987, Ladeira et al., 2001), óxidos de ferro (Pierce \& Moore, 1982, Fuller et al., 1993, Isaacson et al., 1994, Fendorf et al., 1997), óxidos de manganês (Deschamps et al., 2002) e até mesmo a pirita (Zouboulis \& Kydros, 1993). Para um melhor entendimento da imobilização de certos elementos em substratos naturais, alguns trabalhos foram conduzidos com sedimentos de rios e em determinados tipos de solos (Blakey, 1984, Rodie et al., 1995, Ahmann et al., 1997, Manning \& Martens, 1997). Grande parte dos minerais citados anteriormente está presente em vários solos do território brasileiro e são substratos disponíveis, o que contribui para a viabilidade de sua utilização como adsorventes inorgânicos.

\section{Materiais e métodos}

\subsection{Amostras}

Os materiais denominados solos vermelho, marrom e rejeito foram fornecidos pela Rio Paracatu Mineração S.A. (RPM) e são oriundos da região de Paracatu, Minas Gerais. O material denominado solo amarelo foi fornecido pela Mineração Morro Velho S.A, sendo proveniente da região de Nova Lima, Minas Gerais. As amostras foram inicialmente desaglomeradas e peneiradas em malha de abertura equivalente a $0,59 \mathrm{~mm}$. Posteriormente os materiais foram amostrados utilizando-se a técnica de cone-quarteamento, seguida de amostragem no equipamento Sieving Riffler, da marca Quantachrome Corporation, gerando amostras de cerca de 50 gramas que foram estocadas para uso imediato.

\subsection{Isotermas de Adsorção}

Os experimentos foram realizados em erlenmeyers agitados, vedados, contendo $100 \mathrm{~mL}$ de solução de arsênio e $10 \mathrm{~g}$ de material adsorvente. As soluções de arsênio trivalente e pentavalente foram preparadas através da dissolução dos sais meta-arsenito de sódio ( $\mathrm{AsNaO}_{2} \mathrm{PA}$; 99,0\%; Fluka) e arsenato ácido disódio $\left(\mathrm{Na}_{2} \mathrm{HAsO}_{4} \cdot 7 \mathrm{H}_{2} \mathrm{O}\right.$ PA; $98,5 \%$, Fluka $)$ em água deionizada. $\mathrm{O}$ pH da solução foi ajustado com $\mathrm{NaOH}$ ou $\mathrm{HCl}$ e a força iônica da solução foi ajustada com $\mathrm{NaCl}$ ou $\mathrm{Na}_{2} \mathrm{SO}_{4}$ de acordo com as condições de cada ensaio. A concentração inicial do arsênio em solução variou entre 100 e $1000 \mathrm{mg} / \mathrm{L}$. Ensaios distintos foram realizados para a obtenção de cada ponto da isoterma. O tempo de cada ensaio foi fixado em 24 horas e a temperatura em $25 \pm 0,5^{\circ} \mathrm{C}$. O pH durante o ensaio foi sendo corrigido para um valor predeterminado com $\mathrm{NaOH}$ ou $\mathrm{HCl}$ até a completa estabilização. Ao final de cada experimento, a polpa foi imediatamente filtrada, sendo o filtrado coletado para determinação da concentração final de arsênio total. $\mathrm{O}$ arsênio total inicial e final foi analisado diretamente através de espectrometria de absorção atômica e/ou espectrometria de plasma de acoplamento indutivo (ICP- Spectro Modula).

A quantidade máxima de arsênio adsorvida (Qmax) foi calculada a partir do ajuste da equação de Langmuir, descrita a seguir, aos dados experimentais:

$\mathrm{Q}=\frac{\mathrm{Qmax} \cdot \mathrm{k} \cdot \mathrm{Cf}}{1+\mathrm{k} \cdot \mathrm{Cf}}$

onde:

$\mathrm{Q}=$ quantidade de arsênio adsorvida pelo sólido (mg As/g de sólido adsorvente).

Qmax = quantidade máxima de arsênio adsorvido pelo sólido ( $\mathrm{mg} / \mathrm{g}$ de sólido adsorvente).

$\mathrm{Cf}=$ concentração de arsênio no equilíbrio $(\mathrm{mg} / \mathrm{L})$.

$\mathrm{k}=$ constante.

\subsection{Caracterização Química e Mineralógica}

Devido às variadas condições geológicas de formação dos mesmos, os diversos materiais estudados constituem sistemas complexos, cuja caracteri- 
zação requer a utilização de várias técnicas analíticas. No presente trabalho, foram utilizadas análises químicas via úmida para a identificação e dosagem dos constituintes; fluorescência de raios $\mathrm{X}$ para identificação da composição elementar (equipamento Philips PW 2510), difração de raios $X$ (equipamentos Philips PW 1400 e Philips PW 2400), juntamente com observação em microscópio ótico e microscópio eletrônico de varredura para a determinação da composição mineralógica (modelo Jeol JSM35C); determinação da área superficial específica pelo método BET (Quantachrome modelo Nova 1000); e obtenção da distribuição granulométrica utilizando o equipamento SediGraph 5000 .

\section{Resultados}

\subsection{Isotermas de Adsorção}

Os dados obtidos através do levantamento de isotermas de adsorção estão apresentados em gráficos relacionando a concentração final de arsênio na fase aquosa (mg/L), considerada como concentração de equilíbrio, e a quantidade de arsênio adsorvido pelo sólido (mg de As/g de adsorvente). Devido à escassez de dados na literatura relativos à adsorção de As(III) e por ser essa espécie significativamente mais tóxica e apresentar maior tendência a remobilização que o $\mathrm{As}(\mathrm{V})$, optou-se primeiramente por se trabalhar com a espécie trivalente. A Figura 1 mostra as isotermas para As(III), obtidas em $\mathrm{pH}$ 5,5 para todos os substratos empregados. As linhas sólidas na Figura 1 representam o ajuste dos dados experimentais ao modelo teórico de Langmuir (eq. 1). O erro em torno da média foi calculado em no máximo $5 \%$.

A equação da isoterma proposta por Langmuir tem sido muito utilizada para descrever o fenômeno de adsorção de íons em adsorventes sólidos (Griffin et al., 1977, Pierce \& Moore, 1982, Ghosh \& Yuan, 1987, Isaacson et al., 1994), sendo também empregada nesse estudo. $\mathrm{O}$ modelo de adsorção proposto por Langmuir assume que todos os sítios estão inicialmente livres, não considera reações reversíveis e supõe que as espécies ad- sorvidas interagem somente com um sítio ativo formando uma monocamada. Embora as hipóteses do modelo não sejam sempre atendidas, a equação de Langmuir tem se apresentado bastante de adsorção.

O comportamento das várias amostras, em relação à forma da curva, é bastante similar para todos os casos avaliados, o mesmo sendo observado para outros tipos de solos ou minerais. Utilizando-se da equação de Langmuir (Eq. 1) para o cálculo da capacidade máxima de carregamento (Qmax.), obteveram-se os valores apresentados na Tabela 1 . O erro para os valores de Qmax. foi calculado em no mínimo 1\% e no máximo $4 \%$. Para os casos em que o patamar não estava nitidamente definido, como, por exemplo, para o solo vermelho (Figura 1), o valor de Qmax. foi obtido por extrapolação dos dados originados pela Equação 1 . O coeficiente de correlação mossatisfatória na descrição dos fenômenos

trado na Tabela 1 foi calculado para a forma linearizada da Equação 1 (Cf vs. Cf/Q). O menor coeficiente de correlação foi obtido para o rejeito. Melhores ajustes foram alcançados para as demais amostras.

Observa-se uma diferença significativa em relação à capacidade de carregamento das diferentes amostras. O solo vermelho apresentou o maior carregamento de As(III), com Qmax.=3,6mg/g. Os solos amarelo e marrom tiveram praticamente o mesmo desempenho, com valores de Qmax.=1,0mg/g e Qmax.=0,7mg/ $\mathrm{g}$, respectivamente. A extração máxima calculada para o rejeito foi muito inferior às demais $(\mathrm{Qmax} .=0,1 \mathrm{mg} / \mathrm{g})$ e pode ser considerada insignificante para o proposto nesse trabalho. Dados da literatura (Griffin et al., 1977; Pierce \& Moore, 1982) mostram extrações máximas que variam de $0,1 \mathrm{mg} / \mathrm{g}$ para o caulim até $38,5 \mathrm{mg} / \mathrm{g}$ para um óxido de ferro sintético.

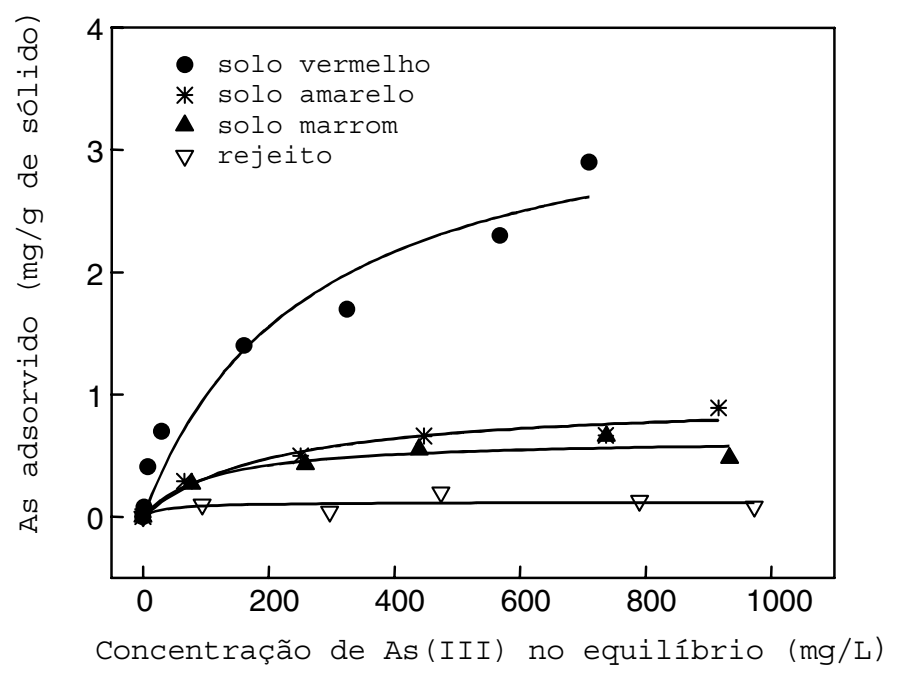

Figura 1 - Remoção de As(III) utilizando-se diferentes adsorventes. Condição das isotermas: $\mathrm{pH}=5,5 ; \mathrm{I}=0,15 \mathrm{M}$ ajustada com $\mathrm{NaCl}$; temperatura de $25 \pm 0,5^{\circ} \mathrm{C}$.

Tabela 1 - Valores de Qmax. para As(III) relativo aos diversos substratos.

\begin{tabular}{c|c|c}
\hline Tipo de Adsorvente & Qmax. (mg/g) & Coeficiente Correlação (Cf) \\
\hline Solo Vermelho & 3,6 & 0,9614 \\
\hline Solo Amarelo & 1,0 & 0,9647 \\
\hline Solo Marrom & 0,7 & 0,9709 \\
\hline Rejeito & 0,1 & 0,9228 \\
\hline
\end{tabular}


Através do levantamento de isotermas, foram também determinadas as capacidades de carregamento em $\mathrm{pH}$ 2,0 e 8,5 de todos os materiais citados anteriormente com relação à espécie trivalente. Para a espécie pentavalente, o carregamento foi avaliado em pH 5,5 e 8,5. A Figura 2 ilustra o desempenho dos materiais, exceto para o solo amarelo, em relação ao $\mathrm{As}(\mathrm{V})$ e pH 5,5. Para todas as condições aplicadas, observou-se a superioridade do solo vermelho comparativamente às demais amostras, com um carregamento de até três vezes mais arsênio do que a segunda melhor amostra (amarela). O desempenho diferenciado do solo vermelho a respeito da adsorção de ambas as espécies de arsênio será discutido a seguir com base na constituição mineralógica e propriedades físicas das amostras.

\subsection{Diâmetro médio superfície específica}

A Tabela 2 indica os valores de d50 (diâmetro médio abaixo do qual se encontram 50\% das partículas) e das áreas superficiais específicas das amostras. A amostra de solo vermelho mostrou-se bastante fina, sendo que $50 \%$ (em massa) das partículas apresentaram valores de diâmetros inferiores a $0,5 \mu \mathrm{m}$. O solo amarelo aparece também com uma granulometria fina apresentando um $\mathrm{d}_{50}=1,2 \mu \mathrm{m}$. A elevada porcentagem de partículas de diâmetro equivalente inferior a $2 \mu \mathrm{m}$ classifica essas amostras como materiais argilosos (Santos, 1975).

Os materiais avaliados possuem áreas superficiais específicas significativamente elevadas, que variaram de 35,7 a $5,2 \mathrm{~m}^{2} / \mathrm{g}$. Os valores obtidos para os solos amarelo e marrom $\left(18,9 \mathrm{e} 16,2 \mathrm{~m}^{2} / \mathrm{g}\right.$, respectivamente) são similares, o mesmo ocorrendo com a composição química e a composição mineralógica, conforme mostrado na próxima seção. Entretanto o solo amarelo é sensivelmente mais fino. Apesar da granulometria mais fina, essa amostra apresentou o valor de Qmax. próximo ao do solo marrom e quase 4 vezes menor ao apresentado pelo solo vermelho (Tabela 1). Portanto, até onde é possível concluir com base nos experimentos conduzidos, não existe correlação entre a granulometria das amostras e sua capacidade de adsorção de arsênio.

\subsection{Caracterização química e mineralógica}

\subsubsection{Composição química}

As análises por fluorescência de

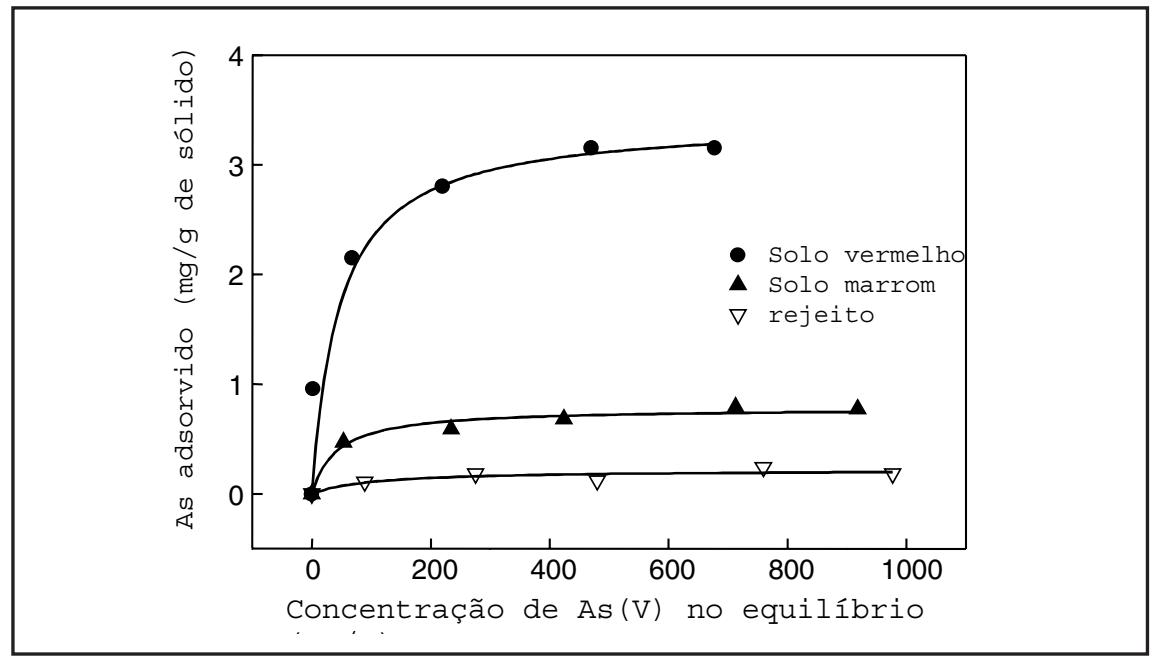

Figura 2 - Remoção de $A s(V)$ utilizando-se amostras de solo vermelho, marrom e rejeito. Condição das isotermas: $\mathrm{pH}=5,5, \mathrm{I}=0,15 \mathrm{M}$ ajustada com $\mathrm{NaCl} ; \mathrm{T}=25 \pm 0,5^{\circ} \mathrm{C}$. As linhas sólidas representam o ajuste dos dados experimentais à Equação 1.

Tabela 2 - Diâmetro médio $\left(d_{50}\right)$ e Superfície específica.

\begin{tabular}{c|c|c|c|c}
\hline Diâmetro $(\mu \mathrm{m})$ & $\begin{array}{c}\text { Solo } \\
\text { vermelho }\end{array}$ & $\begin{array}{c}\text { Solo } \\
\text { marrom }\end{array}$ & Rejeito & $\begin{array}{c}\text { Solo } \\
\text { amarelo }\end{array}$ \\
\hline $\mathrm{d}_{50}$ & $0,5 \mu \mathrm{m}$ & $10 \mu \mathrm{m}$ & $14 \mu \mathrm{m}$ & $1,2 \mu \mathrm{m}$ \\
\hline $\begin{array}{c}\text { Superfície Específica } \\
\left(\mathrm{m}^{2} / \mathrm{g}\right)\end{array}$ & 35,7 & 16,2 & 5,2 & 18,9 \\
\hline
\end{tabular}

Tabela 3 - Composição química dos solos obtida por via úmida.

\begin{tabular}{|c|c|c|c|c|}
\hline Dosagens & $\begin{array}{c}\text { Vermelho } \\
\% \\
\end{array}$ & $\begin{array}{c}\text { Marrom } \\
\%\end{array}$ & $\begin{array}{c}\text { Amarelo } \\
\%\end{array}$ & $\begin{array}{c}\text { Rejeito } \\
\%\end{array}$ \\
\hline $\mathrm{PPC}^{1}$ & 9,4 & 5,5 & 9,2 & 3,3 \\
\hline $\mathrm{Al}_{2} \mathrm{O}_{3 \text { (tot) }}$ & 23,2 & 18,9 & 17,9 & 19,3 \\
\hline $\mathrm{Al}_{2} \mathrm{O}_{3(\mathrm{sol})}{ }^{1}$ & 17,3 & 4,9 & 7,7 & 0,9 \\
\hline $\mathrm{Fe}_{2} \mathrm{O}_{3 \text { (tot.) }}$ & 11,9 & 8,2 & 5,5 & 4,9 \\
\hline $\mathrm{Fe}_{2} \mathrm{O}_{3 \text { (sol.) }}{ }^{2}$ & 10,6 & 5,0 & 4,4 & 2,3 \\
\hline $\mathrm{K}_{2} \mathrm{O}$ & 1,5 & 3,6 & 1,5 & 5,9 \\
\hline $\mathrm{SiO}_{2 \text { (tot) }}$ & 50,5 & 61,0 & 63,2 & 63,7 \\
\hline $\mathrm{SiO}_{2 \text { (silica) }}$ & 44,0 & 57,7 & 48,2 & 41,0 \\
\hline $\mathrm{TiO}_{2}$ & 2,1 & 1,7 & 0,8 & 1,8 \\
\hline Outros $^{3}$ & 1,4 & 1,1 & 1,9 & 1,1 \\
\hline
\end{tabular}

218 REM: R. Esc. Minas, Ouro Preto, 55(3): 215-221, jul. set. 2002 
raios $\mathrm{x}$ indicaram como principais constituintes das amostras os elementos $\mathrm{Si}$, $\mathrm{Al}, \mathrm{Fe}$ e O. Os elementos potássio e titânio aparecem com teor médio e ainda como traços estão os elementos sódio, magnésio e manganês. As análises químicas via úmida (Tabela 3 ) mostraram resultados coerentes com a composição química proveniente da fluorescência de raios x. De acordo com a Tabela 3, os materiais são compostos basicamente de óxidos de silício, alumínio e ferro, estes perfazendo cerca de $85 \%$ dos constituintes. O solo vermelho distingue-se das demais amostras, em especial, pelo elevado teor de óxidos de ferro $(10,6 \%)$ e de alumínio $(17,3 \%$, provavelmente gibbsita) solúveis.

O ferro insolúvel está presente na composição dos silicatos ou nos sulfetos (pirita). Já o silício aparece em destaque devido à presença desse elemento tanto na composição dos argilominerais como na estrutura do quartzo. O silício na forma do mineral quartzo $\left(\mathrm{SiO}_{2 \text { (silica) }}\right)$ é inerte à adsorção de arsênio e, portanto, não contribui para a sua remoção. De todos os adsorventes, o solo marrom é o que apresenta o maior teor de $\left(\mathrm{SiO}_{2 \text { (silica) }}\right)$. No rejeito, a fração de $\mathrm{SiO}_{2}(23 \%)$ resultante da diferença entre o $\mathrm{SiO}_{2(\text { tot })}$ e o $\mathrm{SiO}_{2 \text { (silica) }}$, e que representa o silício presente nos aluminossilicatos, é a mais elevada. Os baixos índices de alumínio solúvel no rejeito vêm comprovar esse fato, já que os aluminossilicatos são formados basicamente de silício e alumínio e são insolúveis em $\mathrm{HCl}$.

\subsubsection{Composição mineralógica}

Os materiais adsorventes avaliados são constituídos por rochas provenientes da decomposição de outras rochas ou minerais e, geralmente, apresentam uma grande variedade de minerais. Para a identificação desses materiais, foi empregada a difração de raios $\mathrm{X}$ e, especificamente para o solo vermelho, foram realizadas análises petrográficas em microscópio ótico e em microscópio eletrônico de varredura/microssonda. Os resultados das análises por difração de raios $\mathrm{X}$ indicam apenas os principais constituintes, uma vez que a técnica apresenta como limitações o problema de superposição de raias e a falta de sensibilidade para constituintes em pequeno teor. $\mathrm{O}$ mineral quartzo $\left(\mathrm{SiO}_{2}\right)$ aparece como abundante (acima de $40 \%$ ) em todos as amostras, o feldspato $\left(\mathrm{K}_{\mathrm{x}}\left(\mathrm{Si}_{3 . \mathrm{x}} \mathrm{Al}_{\mathrm{x}}\right) 0_{8}\right)$, a moscovita $\left(\left(\mathrm{K}, \mathrm{H}_{3} \mathrm{O}\right) \mathrm{Al}_{2}(\mathrm{Si}, \mathrm{Al})_{4} \mathrm{O}_{10}(\mathrm{OH})_{2}\right)$ e a caulinita $\left(\mathrm{Al}_{2} \mathrm{Si}_{2} \mathrm{O}_{5}(\mathrm{OH})_{4}\right)$ aparecem nas quatro amostras em teores que variam de 10 a $<40 \%$. Entretanto o solo vermelho apresenta ainda teor elevado de gibbsita $\left(\mathrm{Al}_{2} \mathrm{O}_{3} \cdot 3 \mathrm{H}_{2} \mathrm{O}\right)$, teores entre $10 \mathrm{a}<40 \% \mathrm{e}$ teores significativos de goethita $(\mathrm{FeOOH})$ e hematita $\left(\mathrm{Fe}_{2} \mathrm{O}_{3}\right)$, entre $3 \mathrm{a}$ $10 \%$. Tendo em vista o melhor desempenho do solo vermelho, foi calculada a composição mineralógica aproximada da amostra (Tabela 4), gerada com base nos dados das análises químicas, difração de raios X e fluorescência descritas anteriormente. Deve-se ressaltar a presença elevada dos óxidos de ferro e alumínio, que, juntos, perfazem um total de $37 \%$ dos constituintes do solo vermelho.

Estudos anteriores (Griffin et al., 1977; Pierce \& Moore, 1982; Fuller et al., 1993; Ladeira et al., 2001) mostraram que amostras de óxidos de ferro, óxidos de alumínio e determinados argilominerais são adsorventes eficientes para o arsênio. Avaliando-se as extrações máximas dos materiais em estudo e respectivas composições químicas e mineralógicas, observou-se que os materiais que apresentaram as mais elevadas extrações foram aqueles que apresentaram, em sua composição, os minerais hematita, goethita e gibbsita. Contrariando alguns dados apresentados na literatura (Griffin et al., 1977), que conferem à caulinita poder adsorvente, o rejeito que é constituído basicamente de quartzo e alumi-

Tabela 4 - Composição aproximada do solo vermelho.

\begin{tabular}{l|c}
\hline \multicolumn{1}{c|}{ Minerais } & Porcentagem \\
\hline Quartzo & $44 \%$ \\
\hline Gibbsita & $26 \%$ \\
\hline Óxidos de Ferro (goethita, hematita) & $11 \%$ \\
\hline Aluminossilicatos (caulinita, moscovita, feldspato) & $16 \%$ \\
\hline Outros minerais menores & $3 \%$ \\
\hline
\end{tabular}

nossilicatos (moscovita e caulinita) foi o pior adsorvente para o arsênio. Entretanto Darland e Inskeep (1997) destacam que o arsenato é preferencialmente adsorvido pelos óxidos de superfície, se comparado aos silicatos constituídos de camadas.

O objetivo da análise petrográfica (Salas, 1996) foi a identificação dos óxidos de ferro e de alumínio e aluminossilicatos, as associações desses minerais e a determinação da distribuição desses componentes de acordo com a faixa granulométrica. Determinar os componentes na fração granulométrica mais fina foi de grande importância, pois, devido à elevada área superficial e à presença de argilominerais, essa é considerada a parte mais ativa dos solos. Além dos constituintes minerais já determinados, os estudos petrográficos apontaram outros minerais, porém na forma de traços, sendo eles: magnetita, martita, pirita, pirrotita, "mineral de titânio" e fragmentos de rocha xistosa muito agregados. Os resultados também mostraram que os aluminossilicatos exibem um avançado processo de oxidação, apresentam-se em finíssimos grãos e na forma de abundantes agregados com tamanhos irregulares e concentrando-se predominantemente na fração menor que $37 \mu \mathrm{m}$. Esses tações de óxidos de ferro hidratados/ goethita e se apresentam com coloração cinza-escura resultante da alteração de óxido de ferro ou com coloração avermelhada resultante da alteração de minerais ferromagnesianos silicatados. Os "minerais transparentes" ocorrem predominantemente na fração maior que $37 \mu \mathrm{m}$, sendo que alguns grãos contêm óxido de ferro. agregados englobam pequenas incrus- 
A análise em microscópio eletrônico de varredura/microssonda mostrou que os óxidos de alumínio se encontram inclusos nos poros do quartzo (Figura 3a). A análise elementar do ponto 1 mostrou uma região constituída de $99 \%$ de quartzo e $0,4 \%$ de alumínio, enquanto que no ponto 2 observa-se um enriquecimento de alumínio até um teor de $60 \%$. Os óxidos de alumínio também aparecem como partículas discretas com teor próximo de $82 \%$. A associação entre óxidos de ferro e aluminossilicatos foi comprovada e está mostrada na Figura 3b, na qual o ponto 4 indica uma região predominantemente formada por aluminossilicatos e o ponto 3 de um óxido de ferro.

\section{Considerações finais}

Os materiais aqui testados como adsorventes não irão passar por processos de dessorção/regeneração e, sim, servir como uma barreira que irá imobilizar o arsênio, evitando a migração desse para o meio ambiente. Portanto é importante que o material utilizado para tal fim tenha uma elevada capacidade de adsorção e seja quimicamente estável. Através das isotermas pôde-se selecionar os materiais mais adequados em relação à capacidade de adsorção, ou seja, aqueles que apresentaram um elevado carregamento de arsênio. A mobilidade química é avaliada em uma outra publicação
(Ladeira et al.,2000). Os dados das isotermas indicam ser o solo vermelho visivelmente superior aos demais materiais em relação à capacidade de remoção de As(III) e As(V). Considerando todas as condições estudadas, o maior valor de Qmax. calculado para esse solo foi 3,6mg/g. O solo marrom e o amarelo apresentaram baixas capacidades de remoção de arsênio $(0,7 \mathrm{mg} / \mathrm{g}$ e $1,0 \mathrm{mg} / \mathrm{g}$, respectivamente), se comparadas à apresentada pela amostra vermelha. $\mathrm{O}$ rejeito apresentou índices de remoção de arsênio próximos a zero em praticamente todas as condições avaliadas.

Além da avaliação comparativa do valor de Qmax de cada amostra, foi importante fazer a relação entre a capacidade de remoção e os constituintes minerais identificados. As amostras são constituídas basicamente por silicatos: quartzo, moscovita, caulinita e feldspato. A amostra de solo vermelho distingue-se das demais amostras por apresentar ainda elevado teor de óxidos de alumínio (26\%) e de óxidos de ferro (11\%), goethita e hematita, preferencialmente. Essa amostra caracteriza-se pela menor granulometria $\left(d_{50}=0,5 \mu \mathrm{m}\right)$ e maior área superficial específica $\left(35,7 \mathrm{~m}^{2} / \mathrm{g}\right)$ entre todos os materiais estudados. Sendo assim, propõe-se que a maior adsorção de arsênio pelo solo vermelho está associada ao maior teor de óxidos de alumínio e de ferro bem como à elevada área superficial específica.
A utilização de solos como adsorventes, oriundos de regiões com potencial para ocorrência de contaminação, foi uma forma de se conhecer o risco imposto ao meio ambiente, caso esse solos fossem contaminados ou utilizados como revestimento em valas de rejeito. Apesar do elevado teor de minerais inertes ao arsênio, o solo vermelho apresentou níveis de carregamento (Qmax.) compatíveis com aqueles determinados para minerais puros (Griffin et al., 1977). Portanto conclui-se que o solo vermelho assim como os demais outros solos com as características anteriormente identificadas apresentam-se com um grande potencial imobilizador do arsênio.

\section{Agradecimentos}

Os autores agradecem ao CNPq, Pronex e ao Instituto do Milênio.

\section{Referências bibliográficas}

AHMANN, D. et alii. Microbial mobilization of arsenic from sediments of the Aberjona Westershed. Environ. Sci. Technol., v. 31, n. 10, p. 2923-2930, 1997.

BLAKEY, N.C. Behavior of arsenical wastes co-disposed with domestic solid wastes. $J$. Water Pollution Control Federation, v. 56, n. 1, p. 69-75, 1984.

DARLAND, J.E., INSKEEP, W.P. Effects of pore water velocity on the transport of arsenate. Environ. Sci. Technol., n. 31, p. 704-709, 1997.
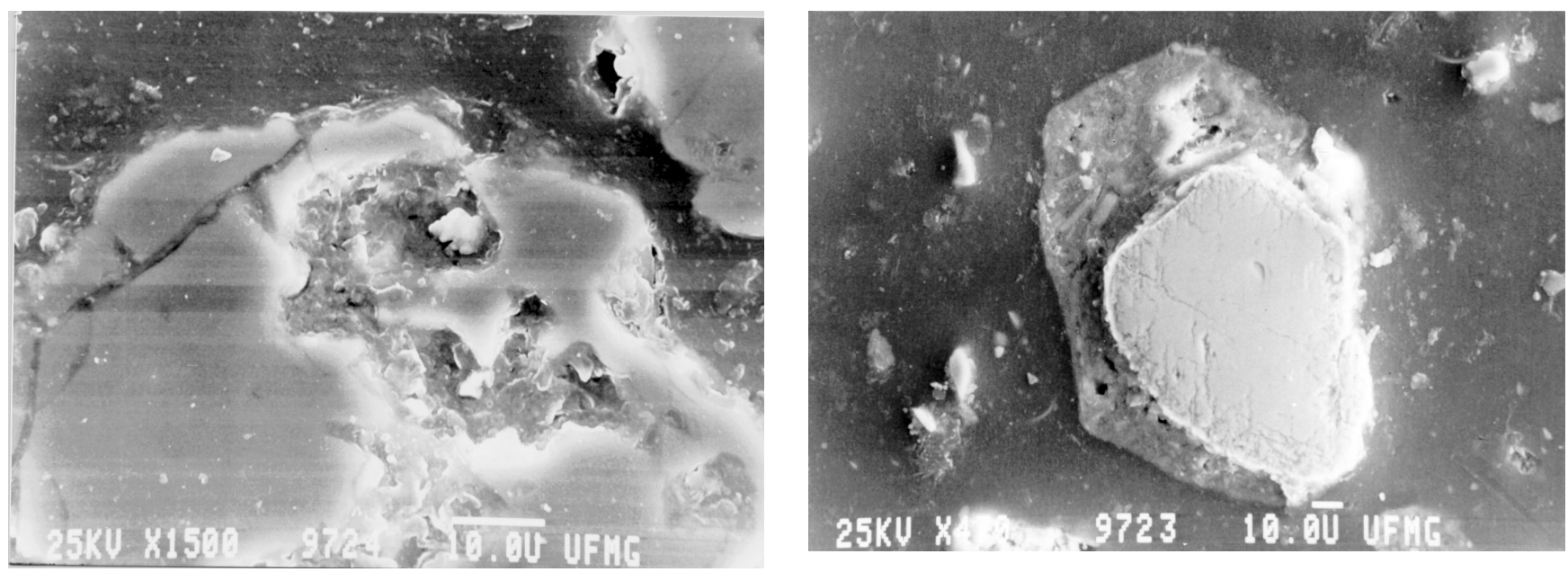

Figura 3 - (a) Solo vermelho $>37 \mu \mathrm{m}$. Ponto $1 \rightarrow \mathrm{Si}=99,2 \% ; \mathrm{Al}=0,4 \% ; \mathrm{Ti}=0,4 \%$. Ponto $2 \rightarrow \mathrm{Si}=30 \% ; \mathrm{Al}=60 \%, \mathrm{Fe}=4 \%, \mathrm{Cl}=6 \%$. (b) $\mathrm{Solo}$ vermelho $>10 \mathrm{~mm}$. Ponto $3 \rightarrow \mathrm{Si}=2 \% ; \mathrm{Al}=2 \%, \mathrm{Fe}=94 \%, \mathrm{Cl}=1 \%, \mathrm{~K}=1 \%$. Ponto $4 \rightarrow \mathrm{Si}=31 \% ; \mathrm{Al}=20 \%, \mathrm{Fe}=24 \%, \mathrm{Cl}=13 \%, \mathrm{~K}=10 \%, \mathrm{Ti}=2 \%$. Imagens obtidas por emissão de elétrons secundários. 
DESCHAMPS, E. et alii. Arsenic sorption onto soils enriched with manganese and iron minerals. Submitted to Clays and Clay Minerals, 2002.

FENDORF, S. et alii. Arsenate and chromate retention mechanisms on goethite. 1. Surface structure. Environ. Sci. Technol., v. 31, n. 2, p. 315-320, 1997.

FENDORF, S. et alii. Mechanism of chromium (III) sorption on silica. 1. Cr(III) surface structure derived by stended X-ray absorption fine structure spectroscopy. Environ. Sci. Technol., n. 28, p. 284-289, 1994.

FULLER, C.C. et alii. Surface chemistry of ferrihydrite: Part 2. Kinetics of arsenate adsorption and coprecipitation. Geo. Cosmo. Acta, n. 57, p. 2271-2282, 1993.

GHOSH, M.M., YUAN, J.R. Adsorption of inorganic arsenic and organoarsenicals on hydrous oxides. Environ. Progress, n. 6, p. 150-157, 1987.

GRIFFIN, R.A. et alii. Attenuation of pollutants in municipal landfill leachate by clay minerals. Environ. Geology Notes, n. 79, p. 1-47, 1997.

ISAACSON, A.E. et alii. Arsenic removal using immobilized ferric oxyhydroxides. In: HARRIS, B., KRAUSE, E. (eds.). Internal. Symp. on Impurity Control and Disposal in Hydrometallurgical Processes. Canada, CIM, p. 47-55, 1994.

LADEIRA A.C.Q. et alii. The use of Al-based adsorbents for arsenic mitigation. In: 6Th SOUTHERN HEMISPHERE MEETINGS ON MINERAL TECHNOL. Anais... Rio de Janeiro, Brazil, p. 549-554, 2001.

LADEIRA A. C. Q., CIMINELLI V. S. T. Mobility of As(III) and As(V) on soils. In: C. YOUNG C. (ed.) Minor Elements 2000 SME, USA, p. 191-198, 2000.

LO, I.M.C. et alIi. Modified clays for waste containment and pollutant attenuation. $\boldsymbol{J}$. Environ. Eng., v. 123, n. 1, p. 25-32, 1997. MANNING, B.A., MARTENS, D.A. Speciation of $\operatorname{arsenic}(\mathrm{III})$ and $\operatorname{arsenic}(\mathrm{V})$ in sediment extracts by high-performance liquid chromatography-hydride generation atomic absorption spectrophotometry. Environ. Sci. Technol., n. 31, p. 171-177, 1997.

PIERCE, M.L., MOORE, C.B. Adsorption of arsenite and arsenate on amorphous iron hydroxide. Water Res., n. 16, p. 1247-1253, 1982.

RAWLINS, B.G. et alii. Preliminary investigation of mining-related arsenic contamination in the provinces of Mendoza and San Juan (Argentina) and Minas Gerais (Brazil). British Geol. Survey Tech. Report WC/97/60. 1997. 27p. Relatório.

RODIE, A. et alii. Biological pathways of arsenic in lakes. Environ. Rev., n. 3, p. 304-307, 1995.

SALAS, H.T. Caracterização de amostra de material argiloso. 1996, 14p. Relatório.

SANTOS, P.S. Tecnologia de argilas; São Paulo: Edgard Blücher Ltda. n. 1, p.339.

ZOUBOULIS, A.I., KYDROS, K.A. Arsenic(III) and arsenic(V) removal from solutions by pyrite fines. Separation Sci. Technol., n. 28, p. 2449-2463, 1993.

\section{Assinatura da REM}

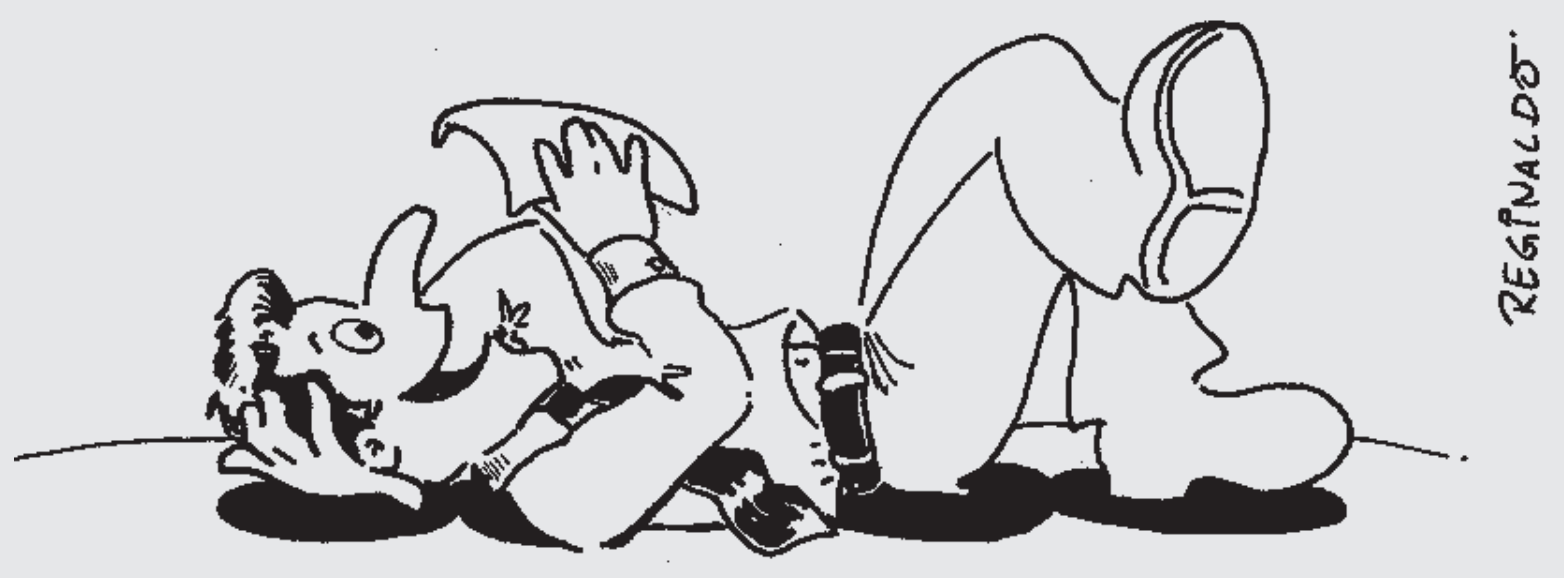

\section{A Rem sabe o quanto VOCÊ é importante.}

Por isso, ela além de manter em dia sua periodicidade, aceitar artigos em cores, reduzir o tempo de publicações dos artigos..., resolveu manter o valor da assinatura para 2002 igual aos valores de 1998, 1999, $2000,2001 .$. 